\title{
LA RESPONSABILIDAD SOCIAL CORPORATIVA EN LAS COOPERATIVAS OLEÍCOLAS DE PRIMER GRADO: LA CREACIÓN DE UN CÓDIGO DE BUEN GOBIERNO COOPERATIVO
}

\author{
THE CORPORATE SOCIAL RESPONSIBILITY AND THE \\ OLIVE COOPERATIVES FIRST GRADE: THE \\ CREATION OF THE CODE OF GOOD GOVERNANCE \\ COOPERATIVE
}

\author{
Juan LATORRE RUIZ ${ }^{1}$
}

Recibido: 05/08/2020

Aceptado: 15/09/2020

SUMARIO. I. Introducción. II. Responsabilidad social corporativa y buen gobierno cooperativo. III. Análisis del código de buen gobierno en las sociedades de capital y su aplicación en los órganos cooperativos. IV. Consideraciones finales. Las normas sobre evaluación y control. V. Bibliografía.

SUMMARY. I. Introduction. II. Corporate social responsibility and good cooperative governance. III. Analysis of the code of good governance in capital societies and its application in cooperative bodies. IV. Final considerations. The rules on evaluation and control saw. V. Bibliography.

Resumen: El presente trabajo versa sobre la aplicación de las normas, indicaciones y recomendaciones sobre responsabilidad social corporativa (en adelante, RSC) y buen gobierno en relación con las cooperativas. Concretamente, las de primer grado, esto es, las más cercanas al territorio en el que desarrollamos nuestro trabajo. El estudio se divide en tres epígrafes, relativos, por una parte, a la justificación de las recomendaciones sobre RSC y buen gobierno en las cooperativas al existir -como es sabido- una estrecha relación entre los principios cooperativistas que rigen estas entidades y la RSC y el buen gobierno; en segundo lugar, haremos referencia a determinados aspectos del código de buen gobierno de las sociedades de capital y su aplicación u observancia en los órganos cooperativos. Finalmente, se concluye con la indicación de las normas y reglas de evaluación y control que, en su caso, entendemos que deben ser una parte esencial si optamos por el análisis de correcta aplicación de las normas de buen gobierno elaboradas así como de su seguimiento y posibles adaptaciones futuras.

Palabras clave: cooperativas oleícolas, gobierno corporativo, código de buen gobierno

Abstract: This work deals with the application of the norms, indications and recommendations on corporate social responsibility (hereinafter, CSR) and good

\footnotetext{
${ }^{1}$ Doctorando del Área de Derecho Mercantil. Facultad de Ciencias Sociales y Jurídicas. Universidad de Jaén. Este trabajo trae causa en las investigaciones derivadas del Proyecto de Investigación "Trust and security in the olive market: Un etiquetado orientado al mercado que informe y proteja a los consumidores", del Instituto de Estudios Giennenses de la Diputación Provincial de Jaén (2020), cuya IP es la Dra. Vázquez Ruano.
} 
governance in relation to cooperatives. Specifically, those of the first degree, that is, those closest to the territory in which we carry out our work. The study is divided into three sections, relating, on the one hand, to the justification of the recommendations on CSR and good governance in cooperatives as there is, as is known, a close relationship between the cooperative principles that govern these entities and CSR and good governance; secondly, we will refer to certain aspects of the code of good governance of capital companies and their application or enforcement in cooperative bodies. Finally, it concludes with the indication of the evaluation and control norms and rules that, where appropriate, we understand should be an essential part if we opt for the analysis of the correct application of the good governance norms elaborated as well as their follow-up and possible future adaptations.

Key words: olive cooperatives, corporate governance, good governance code

\section{INTRODUCCIÓN}

El gobierno corporativo, entendido éste como el conjunto de normas, principios y procedimientos que regulan la estructura y el funcionamiento de los órganos de gobierno de una empresa ${ }^{2}$, se ha convertido en los últimos años en un indicador clave de la buena gestión y responsabilidad social de las empresas. Y su puesta en marcha, en lo que se refiere al sector cooperativo oleícola, supone, no sólo la mejora en la gestión del Consejo de Administración de la cooperativa, esto es, el Consejo Rector, como órgano de decisión, supervisión y control sino también el progreso en cuanto a la participación de los socios en la entidad o el aumento de las relaciones con terceros.

A lo largo de los años, se han ido publicando una sucesión de Códigos de buen gobierno corporativo con el objetivo de establecer una serie de reglas $y$ recomendaciones sobre la estructura de los distintos órganos de gobierno de las empresas y de la actuación de los componentes de dichos órganos.

A nivel internacional, a principios de los años noventa del siglo pasado se publicó en Gran Bretaña un Código de buen gobierno denominado "Aspectos financieros del gobierno corporativo" cuyas recomendaciones se han utilizado para la redacción de otros códigos de buen gobierno. En el año 2002, una serie de expertos de alto nivel seleccionados por la Comisión Europea, elaboraron un informe para la reforma y modernización del derecho societario en Europa. El Informe, conocido como "Informe Winter" en honor al presidente de dicha comisión de expertos, incorporó las prácticas de buen gobierno corporativo. En nuestro país, el primer documento que se

\footnotetext{
2 La OCDE (2016), en “Principios de Gobierno Corporativo de la OCDE y del G20”, Éditions OCDE, Paris, pág. 9. http://dx.doi.org/10.1787/9789264259171-es define "El gobierno corporativo de una sociedad implica el establecimiento de un conjunto de relaciones entre la dirección de la empresa, su consejo de administración, sus accionistas y otros actores interesados. El gobierno corporativo proporciona también la estructura a través de la cual se fijan los objetivos de la sociedad y se determina la forma de alcanzarlos y supervisar su consecución”
} 
publicó fue el Código Olivencia en febrero de $1998^{3}$. Posteriormente, en el año 2003, se publicó el Informe de la Comisión Especial para el fomento de la transparencia y seguridad en los mercados y en las sociedades cotizadas, mas conocido como "Código Aldama" 4 . Ambos, el Código Olivencia y Aldama, fueron la base para la publicación en el año 2006 de Código Unificado de buen gobierno de las sociedades cotizadas, aprobado por acuerdo del Consejo de la Comisión Nacional del Mercado de Valores $(\mathrm{CNMV})^{5}$.

Debido a diversos cambios normativos que afectaron a la modificación de varias de sus recomendaciones y con el objetivo de adaptar o suprimir aquellas disposiciones afectadas por la nueva legislación, el consejo de la Comisión Nacional del Mercado de Valores aprobó una actualización parcial del Código Unificado. Este nuevo Código de buen gobierno de las sociedades cotizadas fue aprobado por Acuerdo del Consejo de la CNMV de 18 de febrero de $2015^{6}$.

La aplicación de dichas recomendaciones y normas en las sociedades cooperativas oleícolas presenta algunas dificultades debido al carácter democrático de la gestión de la cooperativa, entendiendo el mismo como el peso esencial que representa la participación del socio en este tipo social, su diversidad y los diferentes criterios en la toma de decisiones. Así, en las cooperativas, los socios deciden de los asuntos de la cooperativa, eligen y controlan a sus representantes a través de la Asamblea General. Dicho lo cual, debemos analizar si el Código Unificado de buen gobierno, se puede aplicar a las sociedades cooperativas oleícolas de primer grado, o bien, si existe la conveniencia de elaborar uno propio para este tipo social.

$\mathrm{Si}$, con carácter general, para gran parte de las empresas, la Responsabilidad Social Corporativa no les aporta ningún beneficio o ventaja, aún más, para aquellas en la que la gestión corresponde generalmente a los socios cuya gestión principal consiste en sacar adelante la producción de sus aceites sin tener en cuenta otros aspectos en los que los beneficios son también importantes como parte de la gestión económica.

Las cooperativas oleícolas deben, a nuestro entender, responder a los nuevos planteamientos de gestión empresarial que pasan por incorporar en el ámbito de su funcionamiento y gestión, las normas sobre responsabilidad social corporativa con el objetivo de mejorar no sólo el funcionamiento y la imagen de la misma sino al mismo tiempo dar respuesta a una demandada de la ciudadanía. Los miembros del Consejo Rector de las cooperativas deben entender que la cooperativa no sólo debe generar beneficios económicos sino también sociales.

Además, la doctrina económica y la práctica empresarial nos sugiere que los resultados económicos de las empresas mejoran cuando las mismas no sólo se preocupan de maximizar sus beneficios sino también cuando son socialmente responsables. Por tanto, a largo plazo, conviene pensar en la aplicación de las normas sobre RSC si se quiere obtener el éxito empresarial ya que las cooperativas oleícolas además se relacionan cada vez más con operadores a nivel internacional.

\footnotetext{
${ }^{3}$ Véase "El Gobierno de las Sociedades Cotizadas". Comisión especial para el estudio de un Código Ético de los Consejos de Administración de las Sociedades. Madrid, 26 de febrero de 1998. https://www.cnmv.es/DocPortal/Publicaciones/CodigoGov/govsocot.pdf

${ }^{4}$ Véase "Informe de la Comisión Especial para el fomento de la transparencia y seguridad en los mercados $y$ en las sociedades cotizadas". Madrid, 8 de enero de 2003. https://www.cnmv.es/DocPortal/Publicaciones/CodigoGov/INFORMEFINAL.PDF

${ }^{5}$ En adelante Código Unificado.

${ }^{6}$ Código de Buen Gobierno de las Sociedades Cotizadas. Comisión Nacional del Mercado de Valores. Febrero, 2015.
} 
Pues bien, a lo largo del estudio analizaremos la aplicación de las normas, indicaciones y recomendaciones incluidas en dicho código sobre responsabilidad social corporativa (en adelante, RSC) y buen gobierno en relación con las cooperativas oleícolas. Concretamente, a las de primer grado, esto es, las más cercanas al territorio en el que desarrollamos nuestro trabajo y, por consiguiente, por las que por diversas causas que analizaremos a continuación presentan dificultades respecto de la atención con eficacia y profesionalidad de dichas recomendaciones y principios.

El estudio se divide en tres epígrafes, relativos, por una parte, a la justificación de las recomendaciones sobre RSC y buen gobierno en las cooperativas al existir -como es sabido- una estrecha relación entre los principios cooperativistas que rigen estas entidades y la RSC y el buen gobierno; en segundo lugar, haremos referencia a determinados aspectos del código de buen gobierno de las sociedades de capital y su aplicación u observancia en los órganos cooperativos. Finalmente, se concluye con la indicación de las normas y reglas de evaluación y control que, en su caso, entendemos que deben ser una parte esencial si optamos por el análisis de correcta aplicación de las normas de buen gobierno elaboradas así como de su seguimiento y posibles adaptaciones futuras.

\section{RESPONSABILIDAD SOCIAL CORPORATIVA Y BUEN GOBIERNO COOPERATIVO. LOS PRINCIPIOS COOPERATIVOS.}

Aun cuando la responsabilidad social corporativa o empresarial tiene una definición amplia y no homogénea basada en diversos criterios según el organismo o, en su caso, la interpretación de la doctrina que la define, para el caso que nos ocupa de estudio hemos creído conveniente delimitarla en razón de los siguientes aspectos. Es decir, entendida como "el compromiso continuo por parte de las empresas (cooperativas) a comportarse de forma ética y contribuir al desarrollo económico sostenible, al tiempo que se mejora la calidad de vida de los trabajadores y sus familias así como la comunidad local y la sociedad en general" ${ }^{7}$, reproduciendo de este modo, elementos extraídos del Concepto aportado por la World Business Council on Sustainable Development en el año 2002.

En consecuencia, se trata en primer lugar, de tomar conciencia de las consecuencias que se ocasionan con objeto de las acciones que van desarrollando las entidades en su actividad empresarial y, por otra parte, enfocar la gestión hacia las necesidades de los socios cooperativistas y, al mismo tiempo, equilibrar los intereses de los diferentes grupos afectados por el funcionamiento de la cooperativa ya sean consumidores, trabajadores, competidores o la comunidad local.

A pesar de que la Comisión Europea en el año 2002 ya indicó que "las cooperativas tienen una larga tradición en combinar viabilidad económica y responsabilidad social gracias al diálogo entre las partes interesadas y a la gestión participativa, lo cual es óbice para servir de referencia a otras organizaciones”, realidad nos sugiere todo lo contrario ya que la implementación de políticas o acciones sobre responsabilidad social corporativa en el ámbito de las cooperativas de primer grado está poco extendida, aun cuando desde el punto de vista teórico sus principios

\footnotetext{
${ }^{8}$ La propia Comisión Europea reconocía ya en su Comunicación de 2 de julio de 2002 relativa a la responsabilidad social de las empresas: una contribución empresarial al desarrollo sostenible COM 2002 347 final
} 
sean equivalentes a los que integran la RSC o desarrollan algunas políticas aisladas calificadas como "socialmente responsables".

Los principios del cooperativismo de la Alianza Cooperativa Internacional (ACI) y los que propone la Comisión Europea para la promoción de la responsabilidad social están íntimamente vinculados.

La norma de cooperativas nacional ${ }^{9}$ y las autonómicas ${ }^{10}$ responden en su articulado a los principios cooperativos ${ }^{11}$. Es preciso recordar que dichos principios son la guía o modelo de acción para las sociedades cooperativas. Así, el Reglamento de la Alianza Cooperativa Internacional, determina en siete principios, el modelo a seguir. El primero de ellos hace referencia a la adhesión voluntaria y abierta. De este modo cualquier persona que quiera formar parte de una cooperativa y hacer uso de sus servicios podrá hacerlo sin discriminación de ningún tipo, siempre y cuando acepten las responsabilidades que se deriven de tal decisión.

El segundo de ellos destaca el control democrático que se ejerce por parte de los miembros. Los mismos participan tanto de las decisiones como de las líneas de actuación que se decidan poner en marcha en la cooperativa y son responsables de ellas. Igualmente señala el principio de "un socio, un voto" como regla fundamental en las cooperativas de primer grado a la hora de la toma de decisiones y admite otras posibilidades de voto en las cooperativas de otro nivel siempre y cuando se respete la organización democrática de la misma.

El tercero de los principios que señala el reglamento, hace alusión a las cuestiones económicas de la cooperativa y a cómo sus miembros participan y gestionan el capital de la entidad proponiendo una serie de fines para destinar los fondos excedentarios. El crecimiento de la sociedad cooperativa, el reparto de fondos entre los socios o el apoyo a otros proyectos de la sociedad son los criterios que marca dicho principio.

La autonomía e independencia son premisas sin las cuáles no se entiende, a nuestro entender, el funcionamiento adecuado de cualquier organización. Por ello, el principio número cuatro destaca el autogobierno, entendido éste, como la facultad de la

\footnotetext{
${ }^{9}$ Ley 27/1999, de 16 de julio, de Cooperativas. BOE núm. 170, de 17/07/1999

10 Cataluña.- Ley 12/2015, de 9 de julio, de cooperativas. «BOE» núm. 194, de 14 de agosto de 2015. Castilla la Mancha.- Ley 11/2010, de 4 de noviembre, de Cooperativas de Castilla-La Mancha. «BOE» núm. 37, de 12 de febrero de 2011. Madrid.- Ley 4/1999, de 30 de marzo, de Cooperativas de la Comunidad de Madrid. «BOE» núm. 131, de 2 de junio de 1999. Castilla y León.- Ley 4/2002, de 11 de abril, de Cooperativas de la Comunidad de Castilla y León. «BOE» núm. 116, de 15 de mayo de 2002. Galicia.- Ley 5/1998, de 18 de diciembre, de Cooperativas de Galicia. «BOE» núm. 72, de 25/03/1999. Islas Baleares.- Ley 1/2003, de 20 de marzo, de Cooperativas de las Illes Balears. «BOE» núm. 91, de 16 de abril de 2003. La Rioja.- Ley 4/2001, de 2 de julio, de Cooperativas de La Rioja. «BOE» núm. 172, de 19 de julio de 2001. Murcia.- Ley 8/2006, de 16 de noviembre, de Sociedades Cooperativas, de la Región de Murcia. «BOE» núm. 111, de 9 de mayo de 2007. Asturias.- Ley 4/2010, de 29 de junio, de Cooperativas. «BOE» núm. 232, de 24 de septiembre de 2010. Comunidad Valenciana. - Decreto Legislativo 2/2015, de 15 de mayo, del Consell, por el que aprueba el texto refundido de la Ley de Cooperativas de la Comunitat Valenciana. Navarra.- Ley Foral 14/2006, de 11 de diciembre, de Cooperativas de Navarra. <<BOE>> núm. 4 de 04 de Enero de 2007. Andalucía.- Ley 14/2011, de 23 de diciembre, de Sociedades Cooperativas Andaluzas. «BOE» núm. 17, de 20 de enero de 2012. Cantabria.Ley 6/2013, de 6 de noviembre, de Cooperativas de Cantabria. «BOE» núm. 284, de 27 de noviembre de 2013

11 Art. 7 del Reglamento de la Alianza Cooperativa Internacional Adoptado por la Asamblea General el 11 de abril de 2013
} 
La responsabilidad social corporativa en las cooperativas oleícolas de primer grado: la creación de un código de buen gobierno cooperativo

propia entidad para tomar decisiones con independencia y según el criterio o parecer de los socios.

Las cooperativas son organizaciones que deben ofrecer no sólo la posibilidad de participar de un proyecto común sino que también deben ofrecer a sus socios la posibilidad de recibir formación para capacitarlos y poder ayudar al desarrollo de la entidad así como de la importancia de destacar los beneficios que supone la cooperación, especialmente entre los jóvenes ${ }^{12}$.

Para finalizar, el reglamento alude a la cooperación entre cooperativas como uno de los objetivos fundamentales que determinan la fortaleza y la eficacia de este tipo de sociedades frente a otro tipo de empresas y al trabajo en interés por la comunidad como una de las razones fundamentales para el desarrollo del territorio donde se ubican $^{13}$.

Pues bien, una vez analizados los principios cooperativos conviene que hagamos un análisis de la vinculación de los mismos, con las Líneas Directrices de la Organización para la Cooperación y el Desarrollo Económico (OCDE) para Empresas Multinacionales $^{14}$ y que son principios de gobierno corporativo. Este organismo internacional establece un total de quince principios básicos de Responsabilidad Social Corporativa $^{15}$.

12 Principio número 5 del artículo 7 del Reglamento de la ACI.
13 Principio número 6 y 7 del artículo 7 del Reglamento de la ACI.
${ }^{14}$ OCDE (2013), Líneas Directrices de la OCDE para Empresas Multinacionales, OECD Publishing.
http://dx.doi.org/10.1787/9789264202436-es
15 OCDE (2013), Líneas Directrices de la OCDE para Empresas Multinacionales, OECD Publishing. http://dx.doi.org/10.1787/9789264202436-es, pág. 22 y 23. “Las empresas deberán tener totalmente en cuenta las políticas establecidas en los países en los que ejercen su actividad y considerar las opiniones de las demás partes interesadas. A este respecto, A. Las empresas deberán: 1. Contribuir al progreso económico, social y medioambiental para lograr un desarrollo sostenible. 2. Respetar los derechos humanos internacionalmente reconocidos de las personas afectadas por sus actividades. 3. Estimular la generación de capacidades locales mediante una cooperación estrecha con la comunidad local, incluyendo los intereses de los empresarios, y desarrollando al mismo tiempo las actividades de la empresa en los mercados interno y externo de una manera compatible con la necesidad de prácticas comerciales saludables. 4. Fomentar la formación del capital humano, especialmente creando oportunidades de empleo y ofreciendo capacitación a los empleados. 5. Abstenerse de buscar o de aceptar exenciones no contempladas en el marco legal o regulatorio relacionadas con los derechos humanos, el medioambiente, la salud, la seguridad, el trabajo, el sistema tributario, los incentivos financieros u otras cuestiones varias. 6. Apoyar y defender los principios de buen gobierno corporativo y desarrollar e implementar buenas prácticas de gobierno corporativo, incluso a través de grupos de empresas. 7. Desarrollar e implementar prácticas autodisciplinarias y sistemas de gestión eficaces que promuevan una relación de confianza recíproca entre las empresas y las sociedades en las que ejercen su actividad. 8. Promover el conocimiento y el cumplimiento, por parte de los empleados de las empresas multinacionales, de las políticas de empresa mediante la difusión adecuada de las mismas, incluso a través de programas de capacitación. 9. Abstenerse de tomar medidas discriminatorias o disciplinarias contra los trabajadores que elaboren, de buena fe, informes para la dirección o, en su caso, para las autoridades públicas competentes acerca de prácticas contrarias a la ley, a las Directrices o a las políticas de la empresa. 10. Implementar la debida diligencia basada en los riesgos incorporándola, por ejemplo, a sus sistemas de gestión de riesgos, con el fin de identificar, prevenir o atenuar los impactos negativos, reales o potenciales, que se describen en los apartados 11 y 12 e informar sobre cómo se reacciona ante dichos impactos negativos. La naturaleza y el alcance de la debida diligencia dependen de las circunstancias de cada situación particular. 11. Evitar que las actividades propias generen o contribuyan a generar impactos negativos en los campos contemplados por las Directrices y tomar las medidas necesarias para tratarlos cuando se produzcan dichos impactos. 12. Esforzarse por impedir o atenuar los impactos negativos, aun en los casos en que las empresas no hayan contribuido a los mismos, si están directamente relacionados con sus actividades, productos o servicios en virtud de una relación comercial. Esto no ha de interpretarse como una 
En esta ocasión nos hemos centrado en los principios de RSC establecidos por la OCDE en dicho documento ya que existen "numerosas recomendaciones derivadas tanto de la propia definición del concepto de responsabilidad social corporativa como de las recomendaciones que al respecto hacen los organismos internacionales para que las empresas adopten una conducta empresarial responsable” (Mozas, 2010).

Sin duda alguna del análisis de dichas recomendaciones podemos extraer varias conclusiones. Por una parte, al hacer una comparación uno a uno entre los principios cooperativos expuestos y los aludidos sobre RSC-en nota a pie de página-, podemos afirmar que existe una correspondencia entre ambos. Los principios cooperativos que más presencia tienen son el de cooperación entre cooperativas, el principio de educación, formación e información y el principio de interés por la comunidad. Por otra parte, habría que afirmar que la RSC, forma parte consustancial de las sociedades cooperativas ya que no sólo desarrollan su actividad de forma responsable, sino que lo hacen bajo unos principios de responsabilidad social.

Podemos decir, por tanto, que la RSC (en su triple vertiente económica, social y ambiental) concuerda con las cualidades y fundamentos o principios cooperativos. No obstante, esto no sólo debe abordarse desde un análisis comparativo sino más bien desde la acción de establecer unos presupuestos de buen gobierno corporativo.

\section{ANÁLISIS DEL CÓDIGO DE BUEN GOBIERNO DE LAS SOCIEDADES DE CAPITAL Y SU APLICACIÓN EN LOS ÓRGANOS COOPERATIVOS}

El código de buen gobierno de las sociedades de capital supone un elemento clave a la hora de analizar cuál sería el camino a seguir para abordar la elaboración de un código de buen gobierno corporativo para el sector cooperativo. No sería éste el único camino a seguir, ya que, en la actualidad, existen algunos reglamentos de carácter interno en sociedades cooperativas que responden a este último objetivo ${ }^{16}$.

No obstante, debemos analizar a continuación, el Código Unificado de las sociedades de capital y extraer del mismo cuáles serían las indicaciones que pueden tenerse en cuenta a la hora de crear el Código de buen gobierno para las sociedades cooperativas oleícolas de primer grado.

Es por ello por lo que vamos a centrarnos principalmente en los órganos sociales de la cooperativa, la Asamblea General, el Consejo Rector y la Intervención analizando las principales recomendaciones del Código Unificado y distinguiendo las propuestas que pueden ser asumidas por las sociedades cooperativas de primer grado y las que de ninguna forma pueden ser tomadas en cuenta.

En primer lugar, y en referencia a la Asamblea General, vamos a analizar varias recomendaciones del Código Unificado al objeto de establecer si podrían ser tenidas en cuenta o no. La recomendación número uno dispone que los estatutos de las

transferencia de la responsabilidad de la entidad que causa el impacto negativo hacia la empresa con la que mantiene una relación comercial. 13. Además de responder a los impactos negativos en los ámbitos contemplados por las Directrices, fomentar, en la medida de lo posible, que sus socios comerciales, incluidos sus proveedores y contratistas, apliquen principios de conducta empresarial responsable conformes con la Directrices. 14. Comprometerse ante las partes interesadas facilitándoles posibilidades reales de participación a la hora de planificar y tomar decisiones relativas a proyectos u otras actividades susceptibles de influir de forma significativa en las poblaciones locales. 15. Abstenerse de cualquier injerencia indebida en las actividades políticas locales.”

${ }^{16}$ Como ejemplo de ellos véase el Reglamento del Comité de Auditoría y Cumplimiento de Eroski S. Coop. (Aprobado por el 30 de abril de 2013 por el Consejo Rector de Eroski, S. Coop.). 
sociedades cotizadas no deben limitar el número máximo de votos que pueda emitir un mismo accionista, ni contener otras restricciones que dificulten la toma de control de la sociedad mediante la adquisición de sus acciones en el mercado. Esta recomendación parece no estar en consonancia con el objetivo de un buen gobierno corporativo, donde es prioritario evitar problemas de concentración de poder y control como así lo dispone la norma para las cooperativas de primer grado objeto de este análisis (Vilar, 2009). Tal es así que, tanto la Ley nacional de Cooperativas como las autonómicas, establecen el principio de "un socio, un voto" como la fórmula que mejor responde al principio de gestión democrática de las sociedades cooperativas formulado por la Alianza Cooperativa Internacional (ACI).

No obstante, tendríamos que decir que, a pesar de ello, la tendencia actual sugiere responder a aquellos socios cuya aportación a la actividad cooperativizada de la cooperativa es mayor y por tanto "reconocer mayor nivel de participación en los órganos sociales. Así las cosas, el socio que más actividad cooperativizada realice, más poder de decisión debe tener en la sociedad cooperativa, lo que se traduce en un sistema de voto plural proporcional a la actividad cooperativizada" 17.

El artículo 26 de la LC consagra la regla general de "un socio, un voto" al regular el derecho de voto estableciendo en su apartado primero que "cada socio tendrá un voto en la Asamblea General” para, a continuación, fijar la posibilidad de un sistema de voto distinto en las cooperativas de primer grado en base al volumen de la actividad cooperativizada del socio ${ }^{18}$.

Dicho lo cual, podríamos pensar que la permisividad de la norma con la posibilidad de que un socio tenga más de un voto supone el que un grupo de socios mayoritario controle con sus votos la toma de decisiones por parte de la Asamblea General de la cooperativa. Sin embargo, las distintas normas cooperativas, previendo tal posibilidad, establecen una serie de límites para impedir que uno o un grupo de socios obtengan la mayoría del número de votos necesario para la aprobación o no de un determinado acuerdo. Como ejemplo de ello, la LC establece que en el caso de las cooperativas agrarias, si los Estatutos prevén el voto plural ponderado, el mismo no podrá superior en cualquier caso a cinco votos sociales y menos de un tercio de votos de la cooperativa para un solo socio ${ }^{19}$. Por tanto, el Código de Buen Gobierno de las cooperativas oleícolas no podría establecer, en consonancia con lo expuesto anteriormente, ningún sistema de reparto de votos entre los socios cooperativos distinto al dispuesto por la norma.

El Código Unificado establece en su recomendación número tres un deber de información verbal por parte del presidente del consejo de administración, durante la celebración de la junta general ordinaria sobre los aspectos más destacados del gobierno corporativo $^{20}$. Pues bien, esta recomendación, no prevista en la norma de cooperativas,

\footnotetext{
${ }^{17}$ Véase la Tesis Doctoral de Santos Domínguez, M.A. "El poder de decisión del socio en las sociedades cooperativas: la asamblea general”, pp. 577.

18 Artículo 26.2 de la LC "Sin perjuicio de lo dispuesto en el apartado anterior, en las cooperativas de primer grado, los Estatutos podrán establecer el derecho al voto plural ponderado, en proporción al volumen de la actividad cooperativizada, para los socios que sean cooperativas, sociedades controladas por éstas o entidades públicas. En estos supuestos los Estatutos fijarán con claridad los criterios de proporcionalidad, sin que el número de votos de un socio pueda ser superior al tercio de los votos totales de la cooperativa”.

19 Art. 26.4 de la LC

${ }^{20}$ Recomendación 3 del Código Unificado “Que durante la celebración de la junta general ordinaria, como complemento de la difusión por escrito del informe anual de gobierno corporativo, el presidente del
} 
bien podría tenerse en cuenta a la hora de elaborar el Código de Buen Gobierno en las Cooperativas Oleícolas al establecer que el Presidente del Consejo Rector deberá dar cuenta de forma verbal durante la celebración de la Asamblea General de socios de la cooperativa, de los aspectos más destacables del gobierno corporativo de la entidad.

Las cooperativas oleícolas de primer grado celebran, generalmente, su asamblea general de socios cuando es preceptivo o bien cuando el asunto a debatir es de tal importancia que no procede la espera para la celebración de forma ordinaria. A su vez, la participación de los socios en la misma es, por lo general, bastante escasa y poco participativa. La recomendación número siete ${ }^{21}$ del Código Unificado va en consonancia con ampliar, mejorar y facilitar la participación de los socios de la cooperativa en la Asamblea General a través de medios telemáticos de forma que el Código de Buen Gobierno tendría que incluir la obligación de transmitir las Asambleas de la cooperativa de forma telemática así como el proceso de votación.

En cuanto al Consejo Rector, como órgano de gestión y representación de la cooperativa, le corresponde además, no sólo la alta gestión de la entidad y su representación ante terceros sino todas aquellas facultades que no estén reservadas por Ley o por los Estatutos a otros órganos sociales ${ }^{22}$. Pues bien, la recomendación número 4 del Código Unificado ${ }^{23}$ aún no siendo en sus justos términos comparable al tipo social que estamos abordando, como es el de las sociedades cooperativas, si podríamos extraer lo fundamental de su espíritu que no es otro que el Consejo Rector sea capaz de trasladar a sus socios de forma clara, concisa e igualitaria todas aquellas acciones que se promueven y que además se publiquen a través de medios telemáticos.

Así mismo, esta recomendación enlaza con la número seis y nueve ${ }^{24}$ en lo que se refiere a la difusión a través de la página web de la cooperativa de todos aquellos documentos que se consideren de interés para los socios cooperativos. En primer lugar, los informes y documentos obligatorios o voluntarios que debiera publicar el Consejo Rector a través de la página web de la cooperativa con la antelación suficiente a la

consejo de administración informe verbalmente a los accionistas, con suficiente detalle, de los aspectos más relevantes del gobierno corporativo de la sociedad y, en particular: a) De los cambios acaecidos desde la anterior junta general ordinaria. b) De los motivos concretos por los que la compañía no sigue alguna de las recomendaciones del Código de buen gobierno y, si existieran, de las reglas alternativas que aplique en esa materia”

${ }^{21}$ Recomendación 7 del Código Unificado “Que la sociedad transmita en directo, a través de su página web, la celebración de las juntas generales de accionistas.”

22 Art. 32.1 de la LC

${ }^{23}$ Recomendación 4 "Que la sociedad defina y promueva una política de comunicación y contactos con accionistas, inversores institucionales y asesores de voto que sea plenamente respetuosa con las normas contra el abuso de mercado y dé un trato semejante a los accionistas que se encuentren en la misma posición. Y que la sociedad haga pública dicha política a través de su página web, incluyendo información relativa a la forma en que la misma se ha puesto en práctica e identificando a los interlocutores o responsables de llevarla a cabo.

${ }^{24}$ Recomendación 6 "Que las sociedades cotizadas que elaboren los informes que se citan a continuación, ya sea de forma preceptiva o voluntaria, los publiquen en su página web con antelación suficiente a la celebración de la junta general ordinaria, aunque su difusión no sea obligatoria: a) Informe sobre la independencia del auditor. b) Informes de funcionamiento de las comisiones de auditoría y de nombramientos y retribuciones. c) Informe de la comisión de auditoría sobre operaciones vinculadas. d) Informe sobre la política de responsabilidad social corporativa. Recomendación 9 “Que la sociedad haga públicos en su página web, de manera permanente, los requisitos y procedimientos que aceptará para acreditar la titularidad de acciones, el derecho de asistencia a la junta general de accionistas y el ejercicio o delegación del derecho de voto. Y que tales requisitos y procedimientos favorezcan la asistencia y el ejercicio de sus derechos accionistas y se apliquen de forma no discriminatoria.” 
celebración de la Asamblea General Ordinaria entendiendo estos como la publicación de todas aquellas cuestiones que se hayan elaborado e incluso tengan que ser tenidos en cuenta por la Asamblea General de socios a la hora de la deliberación de cualquier competencia atribuida por el artículo 21 de la Ley de Cooperativas. En segundo lugar, y estableciendo un paralelismo con la recomendación número nueve, la sociedad cooperativa publicará en la web todos aquellos procedimientos e instrucciones que permitan al socio poseer toda la información a su alcance referente al funcionamiento de la sociedad, derechos y obligaciones que les asisten así como modelos y anexos que permitan facilitar al socio no sólo mejorar su información, sino también posibilitar su relación con la misma.

En cuanto a la convocatoria de la Asamblea General regulada en el artículo 23 de la Ley de Cooperativas y siguiendo con el paralelismo establecido anteriormente con el objetivo de instaurar algunas indicaciones para elaborar un Código de Buen Gobierno en las cooperativas oleícolas de primer grado, conviene que nos centremos en el análisis de la recomendación número diez ${ }^{25}$. La norma establece en el apartado tercero del citado artículo que la Asamblea General extraordinaria será convocada a iniciativa del Consejo Rector, a petición efectuada, fehacientemente, por un número de socios que representen el veinte por ciento del total de los votos y, si lo prevén los Estatutos, a solicitud de los Interventores. Es en este caso cuando adquiere sentido esta recomendación del Código Unificado y es que el Código de Buen gobierno de las sociedades cooperativas deberá, a nuestro entender, sugerir la publicación de todos aquellos documentos relacionados con esta convocatoria extraordinaria y ponerlos a disposición de todos los interesados con anterioridad a la celebración de la Asamblea. De esta forma, todos los socios tendrán conocimiento de cómo ha sido la forma de convocatoria de la Asamblea, así como los puntos a debatir en el orden del día.

Por último, en referencia al Consejo Rector, habría que aclarar que la norma de cooperativas nacional está, en parte, en consonancia con lo que establece la recomendación número trece ${ }^{26}$ del Código Unificado en relación con el número de consejeros de la entidad cooperativa. La norma determina en su artículo 33 que el número de consejeros no podrá ser inferior a tres y no establece ningún máximo. No así algunas leyes cooperativas autonómicas como la madrileña ${ }^{27}$ que en su artículo 41 determina que el intervalo del número de consejeros está entre tres y quince miembros. La doctrina considera con carácter general que la posibilidad de que el Consejo Rector lo componga un gran número de miembros supone tener variedad de opiniones pero,

\footnotetext{
25 Recomendación 10 “Que cuando algún accionista legitimado haya ejercitado, con anterioridad a la celebración de la junta general de accionistas, el derecho a completar el orden del día o a presentar nuevas propuestas de acuerdo, la sociedad: a) Difunda de inmediato tales puntos complementarios y nuevas propuestas de acuerdo. b) Haga público el modelo de tarjeta de asistencia o formulario de delegación de voto o voto a distancia con las modificaciones precisas para que puedan votarse los nuevos puntos del orden del día y propuestas alternativas de acuerdo en los mismos términos que los propuestos por el consejo de administración. c) Someta todos esos puntos o propuestas alternativas a votación y les aplique las mismas reglas de voto que a las formuladas por el consejo de administración, incluidas, en particular, las presunciones o deducciones sobre el sentido del voto. d) Con posterioridad a la junta general de accionistas, comunique el desglose del voto sobre tales puntos complementarios o propuestas alternativas”.

${ }^{26}$ Recomendación 13 “Que el consejo de administración posea la dimensión precisa para lograr un funcionamiento eficaz y participativo, lo que hace aconsejable que tenga entre cinco y quince miembros.” ${ }^{27}$ Ley 4/1999, de 30 de marzo, de Cooperativas de la Comunidad de Madrid, «BOE» núm. 131, de 2 de junio de 1999.
} 
por el contrario, en ocasiones puede resultar menos beneficioso a la hora de la toma de decisiones rápidas.

Por su parte, la norma andaluza de cooperativas, concretamente su Reglamento ${ }^{28}$ establece en su artículo 35 una serie de opciones distintas en cuanto a la posibilidad de que forme parte del Consejo Rector un socio "impuesto" en base a una serie de requisitos que establece la norma. Ejemplo de ello es la posibilidad de que las personas socias colaboradoras elijan a un representante en el Consejo Rector en base a su representación o bien a la eventualidad de que la cooperativa cuente con más de cincuenta trabajadores y tenga constituido un comité de empresa y uno de ellos tenga que formar parte del Consejo Rector. Esta última opción aún no siendo habitual que las cooperativas de primer grado lleguen a ese número total de trabajadores, es relevante en cuánto a que implica que se obliga por norma a que forme parte del Consejo Rector uno o varios miembros perteneciente a colectivos que pueden poner en valor algunas observaciones de relevancia para el buen funcionamiento de la entidad.

La norma también prevé la opción de que los Estatutos dispongan que como máximo un tercio del total de miembros del Consejo Rector, sean nombrados consejeros aquellos que no sean socios de la cooperativa y cuyo nombramiento se base en la cualificación profesional, experiencia técnica o empresarial con el objetivo de cumplir de forma más eficaz con las funciones encomendadas a este órgano con la salvedad que no podrán adquirir la condición de Presidente o Vicepresidente del referido Consejo. El Código Unificado va más allá al establecer en su recomendación número diecisiete que el número de consejeros independientes represente, al menos, la mitad del total de consejeros.

Por último, la Intervención es el órgano que fiscaliza a la cooperativa ${ }^{29}$ con el objetivo de consultar, comprobar y verificar toda la documentación y actuaciones que realicen los órganos de la misma. Podríamos decir que se equipara a la Comisión de Auditoría prevista para las sociedades de capital. Son importantes en número las recomendaciones que establece el Código Unificado en relación a la función auditora y de control. En cuánto a aquellas que podrían ser tenidas en cuenta para la elaboración del Código de Buen gobierno para las cooperativas oleícolas debemos centrarnos en tres.

En primer lugar, la recomendación número ocho ${ }^{30}$ en cuánto a que la Intervención vele porque el Consejo Rector presente las cuentas a la Asamblea General sin incluir reparos o bien si los hay, que estén bien justificados por parte de este. Habría que decir que la norma no establece ningún precepto al respeto, tan sólo se limita a indicar que antes de ser presentadas sean censuradas por el interventor y puestas a disposición del Consejo Rector en el plazo máximo de un mes ${ }^{31}$. Por tanto, podría ser esta una de las recomendaciones establecidas en el CBG de las cooperativas en tanto se recomiende al Consejo Rector que presente las cuentas sin reparos o salvedades importantes.

\footnotetext{
${ }^{28}$ Decreto 123/2014, de 2 de septiembre, por el que se aprueba el Reglamento de la Ley 14/2011, de 23 de diciembre, de Sociedades Cooperativas Andaluzas. BOJA núm. 186 de 23 de Septiembre de 2014.

${ }^{29}$ Art. 38.1 de la LC.

${ }^{30}$ Recomendación 8 "Que la comisión de auditoría vele porque el consejo de administración procure presentar las cuentas a la junta general de accionistas sin limitaciones ni salvedades en el informe de auditoría y que, en los supuestos excepcionales en que existan salvedades, tanto el presidente de la comisión de auditoría como los auditores expliquen con claridad a los accionistas el contenido y alcance de dichas limitaciones o salvedades.”

${ }^{31}$ Art. 39 de la LC.
} 
Por otra parte resulta relevante tener en cuenta la recomendación número treinta y nueve ${ }^{32}$ en cuánto a que el Interventor o interventores se designen teniendo en cuenta su capacidad técnica y profesional y que la mayoría de ellos sean interventores no socios o independientes. En este caso, la norma de cooperativas no va acorde con esta recomendación ya que establece que sólo un tercio de los interventores podrá ser designado entre expertos independientes. A nuestro juicio, esta sería otra de las recomendaciones a tener en cuenta en la elaboración del CBG de las cooperativas ya que entendemos fundamental que la Intervención en las cooperativas sea desempeñada por alguien solvente desde el punto de vista técnico y profesional. Por tanto y sin contravenir la norma, el CBG podría establecer que el nombramiento del Interventor o interventores responda a que el socio que se postule para su elección cumpla con una serie de requisitos de solvencia técnica y profesional en relación con el cargo a desempeñar.

Así mismo, sería importante con el objetivo de facilitar su tarea de fiscalización, independencia y control que los Interventores pudieran convocar a cualquier empleado o directivo de la entidad con el objetivo de recabar información que pueda ser tenida en cuenta en el informe de fiscalización. Así, estaríamos en consonancia con lo dispuesto en la recomendación número cuarenta y tres del Código Unificado. ${ }^{33}$

Además, ahondando si cabe, en el asunto del control interno, y siguiendo el hilo argumental del Código Unificado ${ }^{34}$, el CBG de las cooperativas podría incorporar el que la entidad disponga de una comisión o grupo que asuma la función de control interno con el objetivo de velar por el buen funcionamiento de la entidad.

En suma, hemos tratado poner de manifiesto cómo es posible adaptar algunas de las recomendaciones del Código de Buen Gobierno previsto para las sociedades de capital a las sociedades cooperativas de primer grado. Es cierto, que las normas que regulan a las cooperativas no hacen del todo posible una total adecuación al mismo pero sin lugar a dudas conviene tener en cuenta las recomendaciones analizadas con anterioridad, adaptarlas a las características propias del tipo social y con éstas y otras proponer la elaboración de un Código de Buen gobierno acorde con la esencia y peculiaridades de las sociedades cooperativas.

\section{CONSIDERACIONES FINALES. LAS NORMAS SOBRE EVALUACIÓN Y CONTROL}

El buen gobierno de las sociedades cooperativas ha de enfocarse hacia un modelo que sea socialmente responsable, de manera que enriquezca no sólo a los socios, sino también a la sociedad en su conjunto. La esencia de las sociedades cooperativas responde al modelo de buen gobierno corporativo ya que desarrollan su actividad volcadas en prestar un buen servicio a sus socios bajo unas normas que por su

\footnotetext{
32 Recomendación 39 “Que los miembros de la comisión de auditoría, y de forma especial su presidente, se designen teniendo en cuenta sus conocimientos y experiencia en materia de contabilidad, auditoría o gestión de riesgos, y que la mayoría de dichos miembros sean consejeros independientes.”

${ }^{33}$ Recomendación 43. "Que la comisión de auditoría pueda convocar a cualquier empleado o directivo de la sociedad, e incluso disponer que comparezcan sin presencia de ningún otro directivo”.

${ }^{34}$ Recomendación 40. “Que bajo la supervisión de la comisión de auditoría, se disponga de una unidad que asuma la función de auditoría interna que vele por el buen funcionamiento de los sistemas de información y control interno y que funcionalmente dependa del presidente no ejecutivo del consejo o del de la comisión de auditoría.”
} 
naturaleza responden a criterios de buena ética empresarial y social. No obstante existe una falta importante de prácticas de buen gobierno entre las sociedades cooperativas oleícolas de primer grado.

Los documentos y recomendaciones sobre buen gobierno corporativo que se han ido publicando a lo largo de los últimos años en nuestro país se han basado en dotar de normas, recomendaciones y principios a las sociedades de capital, no así para las cooperativas cuya singularidad jurídica y organizativa son completamente distintas.

Dicho lo cual y entendiendo que las sociedades cooperativas no pueden permanecer al margen de estos criterios de buen gobierno corporativo, a lo largo de este estudio hemos analizado la importancia que está adquiriendo la RSC en nuestro país como demuestra la cantidad ingente de iniciativas que se están llevando a cabo en cuanto a su difusión, normalización y certificación. Por otra parte, hemos examinado la vinculación que existe entre los principios cooperativos y los RSC así como las ventajas que pueden obtener las sociedades cooperativas de primer grado al ponerlos en práctica. Y por último, hemos analizado algunas de las recomendaciones incluidas en el Código Unificado de buen gobierno para las sociedades de capital cuyo contenido podría ser adaptado y puesto en práctica por las entidades cooperativas.

En relación a esta cuestión hemos de resumir algunas de estas propuestas que se centran principalmente en la mejora del funcionamiento de los órganos sociales de la cooperativa tales como la Asamblea General, el Consejo Rector y la Intervención. En primer lugar, resulta interesante que el CBG dé un paso más, vaya más allá del principio "un socio-un voto" y establezca la recomendación del sistema de voto plural con los límites marcados en la norma al objeto de mejorar la representación de los socios y respetar la aportación a la cooperativa de cada uno de ellos, permitiendo una representación mayor a aquellos que realizan una mayor aportación a la actividad de la cooperativa.

Por otra parte, el CBG debe establecer una serie de medidas que podríamos aunar bajo el paraguas de la mejora en la transparencia. Por un lado nos referimos a la obligación del Presidente de la Cooperativa de dar cuenta sobre el gobierno corporativo. Resulta fundamental que una vez aprobado un Código de Buen Gobierno, el máximo representante de la entidad, dé información a las socios sobre cómo se está aplicando el mismo en la Asamblea general de la entidad.

Además, aun suponiendo un esfuerzo administrativo para estas entidades, resulta prioritario facilitar a los socios su participación en los órganos de decisión de la cooperativa mediante procedimientos telemáticos, incluyendo la obligación de trasmitir las asambleas online así como el proceso de votación. De esta forma, acabaríamos con la rémora que existe en el sector, sobre la baja participación presencial de los socios en las asambleas de las cooperativas. En relación con esta cuestión, es imprescindible que el CBG incluya la difusión a través de la página web de la cooperativa de todos aquellos documentos que se consideren de interés para los socios cooperativos, información sobre procedimientos generales e instrucciones que permitan al socio disponer de todos los datos de relevancia sobre la entidad así como modelos y anexos que permitan facilitarles y no sólo mejorar su información, sino también posibilitar su relación con la misma.

Es una constante en todos los sectores productivos y empresariales, la incorporación de profesionales con experiencia técnica y empresarial ajenos a la entidad con el objetivo de mejorar la empresa en su conjunto. Pues bien, resulta evidente que el sector cooperativo oleícola no escapa a esta obviedad por lo que el CBG debe prever el 
que puedan incorporarse al Consejo Rector de la cooperativa personas no socias y cuyo nombramiento se base en esa cualificación profesional, experiencia técnica o empresarial con el objetivo de cumplir de forma más eficaz con las funciones encomendadas a este órgano con la salvedad que no podrán adquirir la condición de Presidente o Vicepresidente del referido Consejo.

En última instancia, el CBG debe establecer un apartado referido a la figura de la Intervención. Se trata de uno de los órganos fundamentales de la cooperativa. El CBG deberá exigir, entre otras, que el Consejo Rector presente las cuentas a la Asamblea General sin incluir reparos de la intervención o bien si los hay, que estén bien justificados por parte de éste. Y sobre todo, que el Interventor o interventores sean designados teniendo en cuenta su capacidad técnica y profesional y que la mayoría de ellos sean interventores no socios o independientes. Y por último, que con el objetivo de poder funcionar de forma independiente, el CBG establezca que los mismos puedan convocar a cualquier empleado o directivo de la entidad con el objetivo de recabar información que pueda ser tenida en cuenta en el informe de fiscalización.

Siendo conscientes de que el funcionamiento de las entidades cooperativas es complejo y la práctica societaria se aleja en ocasiones de los principios que les inspira debemos poner de manifiesto que es posible realizar un Código de Buen Gobierno y ponerlo en práctica. Para ello no sólo debe tenerse en cuenta el análisis de las recomendaciones que hemos analizado con anterioridad sino también que dicho Código debe responder a un modelo en el que se prime la participación de los socios en las decisiones e información, que tenga en cuenta los distintos grupos de interés de la cooperativa y sobre todo que no pierda de vista a la sociedad a la que presta sus servicios.

Lo que en este estudio hemos tratado de establecer es un punto de partida interesante a tener en cuenta para un desarrollo posterior por parte del sector cooperativista que permita modernizar la gestión y regulación de estas empresas.

Por último, nos parece oportuno indicar que la creación de un código de buen gobierno en el ámbito cooperativo proporcionará ventajas importantes en la gestión, visión y fortalezas de este tipo de cooperativas. Entiéndase esta parte como la elaboración, difusión y aplicación de unas normas que establezcan unas reglas de buen gobierno corporativo. Ahora bien, aún nos queda pendiente la cuestión de la forma de evaluación y control de la creación de este código de buen gobierno y, en su caso, de su observancia o atención. Se trata de certificar a través de los propios órganos de la cooperativa o bien mediante una entidad u organismo independiente que las acciones de la cooperativa nos indiquen que son socialmente responsables con los principios o recomendaciones establecidas al efecto.

El Código de Buen Gobierno que se elabore no sólo debe contener las recomendaciones que deban ponerse en práctica por la cooperativa sino también la forma para evaluar si todo ello se ha cumplido y en qué forma se ha hecho. Respuesta a ello, puede darse con las competencias que se les puedan atribuir a los administradores de la cooperativa, al Consejo Rector o en última instancia a la asamblea general de socios, referentes a las normas de control mediante la constitución de una comisión de control interno de la entidad compuesta por socios y personal independiente a la propia entidad cooperativa.

Por otra parte cabría precisar que incluso, este control podría llevarse a cabo mediante una supervisión externa, a través de un organismo de control homologado que 
sea capaz de medir si se ha cumplido o no con el CBG y en función de ello si del incumplimiento se derivan una serie de consecuencias para la entidad.

Ambas opciones supondrían una forma de control que puede resultar la fórmula mediante la cual se haga una evaluación de las acciones y recomendaciones de buen gobierno y, en todo caso, en beneficio de los propios socios y de la sociedad al objeto de cumplir la función social y económica que las singulariza.

\section{BIBLIOGRAFÍA}

AA.VV. Tratado de Derecho de Sociedades Cooperativas, (Dir. PEINADO GRACIA, J.I./ Coord. VÁZQUEZ RUANO, T.), Tomo I y II, Tirant lo Blanch, Valencia, 2019.

COMISIÓN NACIONAL DEL MERCADO DE VALORES, Código de buen gobierno de las sociedades cotizadas, Madrid, Febrero 2015.

FELIÚ REY, M.I./ MORILLAS JARILLO, Ma. J., Curso de cooperativas, Tomo I y II, Tecnos, Madrid, 2018.

GÓMEZ-LIMÓN, J.A./ PARRAS ROSA, M., Economía y comercialización de los aceites de oliva. Factores y perspectivas para el liderazgo español del mercado global, Cajamar, 2017.

MINISTERIO DE TRABAJO Y ASUNTOS SOCIALES, La responsabilidad social de las empresas. Diálogo social, Madrid, 2017.

MORILLAS JARILLO, $\mathrm{M}^{\mathrm{a}}$. J., Retos y oportunidades de las sociedades cooperativas andaluzas ante su nuevo marco legal. Comentario a la Ley 14/2011 de Sociedades Cooperativas y su Reglamento de desarrollo (Decreto 123/2014), Dykinson, 2017.

MOZAS MORAL, A./ PUENTES POYATOS, R. La responsabilidad social corporativa y su paralelismo con las sociedades cooperativas, Revista de Estudios Cooperativos, núm. 103, 2010, pp. 75-100, Madrid.

PANIAGUA ZURERA, M./ "Las empresas de la economía social. Más allá del comentario a la Ley 5/2011 de Economía Social”, Marcial Pons, 2011.

PUENTES POYATOS, R./ VELASCO GÁMEZ, Ma M./; VILAR HERNÁNDEZ, J. El buen gobierno corporativo en las sociedades cooperativas, Revista de Estudios Cooperativos, núm. 98, 2009, pp. 118-140, Madrid

SERVER IZQUIERDO, RJ./ CAPÓ VICEDO, J. La Responsabilidad Social Empresarial en un contexto de crisis. Repercusión en las Sociedades Cooperativas, CIRIEC-España, Revista de Economía Pública, Social y Cooperativa, núm. 65, 2009, pp. 7-3, Centre International de Recherches et d'Information sur l'Economie Publique, Sociale et Coopérative, Valencia.

VARGAS SÁNCHEZ, A./ VACA ACOSTA, R. M ${ }^{\mathrm{a}}$. Responsabilidad Social Corporativa y cooperativismo: Vínculos y potencialidades, CIRIEC-España, Revista de Economía Pública, Social y Cooperativa, núm. 53, noviembre, 2005, pp. 241-260, Centre International de Recherches et d'Information sur l'Economie Publique, Sociale et Coopérative, Valencia.

VARGAS VASSEROT, C./ GADEA SOLER. E./ SACRISTÁN BERGIA, F.,/ "Derecho de las sociedades cooperativas. Régimen económico, integración, modificaciones estructurales y disolución”, Tomo I y II, Wolters Kluwer, Madrid, 2017. 
La responsabilidad social corporativa en las cooperativas oleícolas de primer grado:

la creación de un código de buen gobierno cooperativo

VARGAS VASSEROT, C./ "La estructura orgánica de la sociedad cooperativa y el reto de la modernidad corporativa”, CIRIEC número 20/2009. 